\title{
aniki
}

Revista Portuguesa da Imagem em Movimento

Portuguese Journal of the Moving Image

\section{O filme como conjunto de práticas: uma distensão performativa do restauro cinematográfico}

Ricardo Vieira Lisboa ${ }^{1}$

\section{Introdução}

Neste artigo pretendo, numa primeira fase, explicar de que modo, no cinema, dois conceitos fundamentais do restauro como são autêntico e original, carecem de explicitação e compreensão totais recorrendo ao conceito de cópia ideal tipo de Paolo Cherchi Usai, que exemplarmente traduz esse défice. Posto isto, tentarei apresentar alguns argumentos que avaliam o conceito de original, no que respeita ao cinema, como um conceito que manifesta uma ideologia mercantilista de constante renovação monetária do arquivo partindo dos olhares de Nathan Carroll e Vinzenz Hediger. Em terceiro lugar, apresentarei alguns exemplos de filmes que, tendo várias versões, escapam a esses referidos dois conceitos ou, pelo menos, ajudam a esbatê-los. Em particular, referirei dois exemplos em que a noção de versão é uma prática volátil e está em constante atualização (e é aberta a repetidas formas de reescrita). Feita esta análise, proporei a noção de filme como conjunto de práticas, isto é, que se passe a entender uma obra cinematográfica não como um objeto singular e bem limitado material e historicamente, mas pelo contrário, como um objeto plural que apresenta as suas múltiplas versões como um conjunto em permanente atualização. Basear-me-ei de novo numa ideia de Vinzenz Hediger e darei especial atenção ao modo como diferentes práticas musicais e sonoras consubstanciam uma noção aberta de obra cinematográfica. Esta noção de filme como conjunto de práticas no contexto do restauro cinematográfico propõe, assim, em termos práticos (no que respeita à visibilidade pública dos filmes), uma distensão dos objetos fílmicos na proporção múltipla das versões dele conservadas, manifestada no suporte do DVD - mas que poderá expandir-se a outros formatos de consumo de cinema, como os Blu-rays, as plataformas de streaming ou os bundles de torrents - na medida em que "o DVD é um elemento entre muito outros (blogs, bases de dados, portais de vídeo, jogos de computador, festivais, streaming, etc.) característicos das novas formas da cinefilia e da cultura cinematográfica" ${ }^{2}$ (Hagener 2014). Um exemplo do filme como conjunto de práticas, que analisarei adiante, é a edição

\footnotetext{
${ }^{1}$ Mestre pela ESTC - Escola Superior de Teatro e Cinema, 2700-571 Amadora, Portugal.

2 Tradução do autor.
} 
em DVD de três versões distintas de Douro, Faina Fluvial (1931) de Manoel de Oliveira - caso em que a curta-metragem do realizador portuense passa de cerca de 20 minutos para perto de uma hora de duração, com versões que se distinguem pela montagem, mas também, e especialmente, pelos diferentes acompanhamentos sonoros (uma muda e duas sonoras, com diferentes composições musicais). Procurarei perceber de que modo esta edição de múltiplas versões contribuiu de forma pedagógica para a compreensão da história material dos filmes, e, mais do que isso, de que modo traduz os modos como é consumido, hoje, o cinema - tendo para o efeito produzido uma experiência vídeo-ensaística que facilita esse trabalho comparativo.

\section{A dificuldade de encontrar a original e o autêntico no objeto fílmico}

O cinema como arte é ontologicamente diferente de todas as outras, facto que se evidencia nas questões do restauro. Isto acontece porque na sua natureza se encontram dois elementos de extrema complexidade e singularidade: a necessidade de duplicação (que Walter Benjamin interpreta como o fator fundamental na falência da aura mitológica que circunda as outras formas de $\operatorname{arte}^{3}$ - ainda que, naturalmente, o ensaio de 1936 não pudesse prever o processo de secularização da arte do cinema ao longo dos seus mais de cem anos, e muito menos conceber a ideia de cinema em casa e a comercialização de filmes em VHS, DVD, Blu-ray ou Streaming) e a componente performativa (ou performática) do cinematógrafo. Ou, dito de outro modo, "devido à rápida mudança dos meios digitais, o estado da teoria digital está também a evoluir a um ritmo dramático" (Jenkins 2007, 236) e onde se lê teoria digital poderá ler-se, sem esforço, teoria do cinema.

Estes dois fatores dificultam a fixação de termos como original e autêntico quando nos referimos ao cinema. O primeiro é um problema partilhado com obras como as serigrafias e outras artes que impliquem a duplicação ou a impressão. Nestes casos, o original é por vezes tido como o stencil ou o objeto a partir do qual se produzem os duplicados e aí é que reside a natureza artística do trabalho - no entanto, não só as impressões ou duplicados não são

\footnotetext{
3 “Nas obras cinematográficas, a reprodutibilidade técnica do produto não é uma condição imposta do exterior para a sua divulgação em massa, contrariamente ao que sucede, por exemplo, com as obras literárias ou de pintura. A reprodutibilidade técnica da obra cinematográfica tem o seu fundamento diretamente na técnica da sua reprodução. Esta possibilita não só a sua imediata divulgação em massa, como também a impõe. Impõe-na porque a reprodução de um filme é tão cara que alguém que pudesse por exemplo comprar um quadro não poderia certamente darse ao luxo de comprar um filme" (Benjamin 2010, 70).

${ }^{4}$ Tradução do autor.
} 
necessariamente únicos como também não são cópias idênticas entre si. A acrescentar a isto há o caso de que, dependendo da situação, uma impressão ou um duplicado feito por outro que não o artista pode, em certos casos, ser considerado um objeto original e noutros não (Jamieson 2003, 23).

No cinema é difícil fixar um material fílmico que funcione como identidade arquetípica de originalidade. Contudo, Paolo Cherchi Usai propõe o termo tipo ideal definido por Max Weber, em que se defende um objeto utópico ou um conceito idealizado, com finalidade heurística que, como tal, não possui funcionalidade prática, mas ainda assim serve como abstração teórica que acaba por solucionar e resolver algumas questões (Usai 1991, 44). Usai define então o seu termo heurístico:"[o] tipo ideal de uma cópia de um filme é a primeira cópia positiva tirada de um negativo original, no momento da sua primeira projeção" ${ }^{5}$ (op. cit.). Esta definição considera à partida três fatores fundamentais. O primeiro, a materialidade e singularidade de um negativo original (isto é, o negativo de câmara). O segundo, o resultado de uma série de processos técnicos dos quais resultará a primeira cópia positiva, material esse que ainda não constitui uma cópia de tipo ideal, já que o filme não existe antes (ou só existe aquando) da sua projeção, o terceiro factor. Usai refere-se à cópia não projetada como um modelo potencial.

Notem-se aqui as fragilidades deste termo: (a) no cinema mudo, era frequente a existência de mais de um negativo de câmara, já que muitas vezes se filmava com câmaras paralelas; (b) considerase a cópia ideal tipo aquela que se projeta na primeira projeção porque, no momento da projeção, a película sofre micro-alterações que, mesmo não sendo imediatamente visíveis, são-no cumulativamente e destroem a integridade e integralidade da cópia; (c) uma vez que a primeira cópia atingiu um estado de deterioração tal, uma segunda positivação do negativo já será considerada inferior à primeira por desgaste semelhante do negativo, desgaste esse igualmente cumulativo, assim todos os novos positivos são, sucessivamente, materialmente mais distantes da cópia ideal tipo; (d) o cinema digital introduziu uma significativa mudança neste processo, já que nele não se verifica a degradação material do DCDM - Digital Cinema Distribution Master, e, assim, todas as cópias seriam de tipo ideal. Porém, esta ideia é falaciosa, já que os ficheiros digitais não têm uma durabilidade semelhante à da película ${ }^{6}$. Assim, e não considerando a

\footnotetext{
5 Tradução do autor.

${ }^{6}$ Um disco rígido tem uma fiabilidade que ronda as dezenas de anos, ao passo que a película conservada em condições corretas pode preservar-se por mais de um século. No sentido da preservação dos ficheiros digitais, está implicada a constante transferência para sucessivos suportes desses ficheiros, que, pela constante atualização tecnológica, implicam conversões para suportes mais recentes. Este facto, que já constitui o principal problema para os arquivos na transição do
} 
problemática da conservação do cinema digital, a cópia ideal tipo não se traduz num objeto material que se propaga no tempo e se conserva, mas sim num de existência efémera e que cessa de existir no mesmo momento em que se materializa (no ecrã).

O cinema, pela sua natureza reprodutível, de produção em massa e dependente de uma performance sempre variável, e pelas condicionantes próprias da sua história, apresenta-se como área artística que desafia os conceitos básicos do restauro de arte. E as soluções apresentadas até então privilegiam, quase sempre, uma vertente prática para a definição do objeto de restauro, ou, inversamente, uma sem aplicabilidade real.

Por tudo isto, no que respeita ao restauro cinematográfico, está ainda por estabelecer uma teoria geral que defina boas práticas técnicas e equacione de forma sistemática o trabalho do restaurador de um ponto de vista ético e historiográfico, no âmbito da história do cinema.Na sua desconstrução da narrativa do Cinema Forever, no artigo "Unwrapping Archives: DVD restoration Demonstrations and Marketing of Authenticity" (2005), Nathan Carroll corrobora esta falta de unidade teórica do restauro e acrescenta ainda uma outra dificuldade, a componente regional de que cada restauro sempre participa de algum modo:

O que permanece perdido (...) é uma norma universal para o restauro digital que consiga, por si, unir o universo do cinema entre forma e prática. O restauro (...) varia de cultura para cultura, respondendo a diferentes mercados e desejos dos consumidores. $\mathrm{O}$ critério digital para a imagem cinemática ideal varia com diferentes memórias culturais e políticas de preservação. A autoridade cultural é pois relativa a políticas de gosto evolutivas. (Carroll 2005, 24-25) ${ }^{7}$

As próximas páginas tentarão apresentar e defender uma perspetiva diferente para o restauro cinematográfico, que consiste em entender o objeto fílmico não como uma identidade una e concisa, mas antes como um conjunto de identidades - um conjunto de práticas -, distendendo assim o filme pela multiplicidade de versões que dele existam. O original deixa de estar contido numa versão dita definitiva, e passa a existir no espaço de convolução de todas as versões (mesmo que em nenhuma delas, e mesmo que apenas parcialmente). Esta perspetiva permite resolver a questão da originalidade da obra restaurada por negar uma hierarquia de originalidades, remetendo o conceito para uma historiografia das versões fílmicas. Resolve também a problemática do autêntico porque o dilui na multiplicação do objeto fílmico. Esta perspetiva é possível pela natureza duplicativa do cinema, mas, mais do que isso, é

analógico para o digital, promove a degradação/corrompimento do próprio código digital, de modo não muito distinto da degradação material dos suportes analógicos.

${ }^{7}$ Tradução do autor. 
auxiliada, hoje em dia, pela transição do objeto fílmico para o território digital de livre circulação de dados na Web 2.0 - em que a noção de film bundle é uma realidade do universo de partilha de torrents.

\section{A retórica do original}

No que respeita à questão da performance (ou do dispositivo, consoante os termos de cada académico), é possível estabelecer uma distinção entre dispositivos históricos (a noite da primeira exibição pública do filme, a sua estreia comercial, etc.) e a história dos dispositivos (que inclui os vários suportes em que um filme foi sendo mostrado, as suas reconversões de nitrato para celuloide, de película para VHS ou DVD/Blu-ray digital, exibido na televisão ou em streaming online, de HD para $2 \mathrm{~K}$ e agora para $4 \mathrm{~K}, 8 \mathrm{~K}$, e por aí em diante). A autora desta distinção, Giovanna Fossati, não deixa, no entanto, de notar que "é impossível reproduzir o dispositivo histórico como o era originalmente. Aliás, a mesma combinação de filme, público e ambiente é impossível de recrear" ${ }^{8}$ (Fossati 2010, 128), e, como tal, ou deixa de existir performance original ou todas as performances são igualmente originais.

Se se juntar a isto a problemática questão das várias versões, então o conceito de original esvazia-se progressivamente, ao ponto de $\mathrm{o}$ académico Vinzenz Hediger, num artigo intitulado "The Original is Always Lost. Film History, Copyright Industries and the Problem of Reconstruction" (2005) se questionar sobre "quão útil é a noção de original" (Hediger 2005, 136). O investigador encontra motivos económicos e ideológicos por detrás do termo:

Ainda que à noção de original possa faltar um referente preciso (...), chamar à versão restaurada o original tem as suas vantagens para o filme. Muito como a noção de auteur, a noção de original foca a atenção do público, dos média e outras instituições em certos filmes ou obras à qual se associa. Quer se refira a um original existente ou não, a noção de original é uma de princípios estruturais cruciais em qualquer herança artística, separando o que é importante daquilo que não o é, o que merece ser incluído no cânone do que não merece. Destacando um filme e uma versão às custas de outra, a noção de original gera interesses, cria visibilidade e enforma a acessibilidade, ainda que o motivo para a escolha de uma versão possa ser questionável de um ponto de vista historiográfico. (op. cit., 136) ${ }^{10}$

A interpretação do conceito de original como um termo mercantil para a promoção de produtos como edições restauradas em

\footnotetext{
8 Tradução do autor.

9 Tradução do autor.

${ }^{10}$ Tradução do autor.
} 
DVD e Blu-ray é comum a Hediger e ao já referido Nathan Carroll. Onde o primeiro afirma que "a retórica do original sistematicamente sugere que o original já está sempre perdido, para melhor legitimar a necessidade da reconstrução."11 (op. cit., 137), a segunda acrescenta que "o restauro está mais bem inserido no negócio (...) de re-storing, isto é, de rearquivar, a distribuição de memórias fílmicas (...) através da lente reformatada da estética contemporânea e das prioridades económicas."12 (Carroll 2005, 19).

Posto de outro modo, com a transferência da indústria cinematográfica para uma indústria de direitos de autor, na qual um arquivo é uma fonte de rendimento contínuo e confiável, a cunhagem do termo original ganha uma dimensão económica. Só que para se atestar a originalidade de um novo produto tem de se garantir a decadência dos produtos anteriores, produtos esses que substituem e atualizam (segundo os padrões vigentes) a memória dos espectadores.

Segundo Hediger, o procedimento típico destas ações interesseiras de restauro inicia-se pelo estabelecimento da importância do original através da afirmação de existência (mesmo que passada) de um objeto de força emocional e validade artística que merece atenção e sobre o qual se devem dispensar todos os esforços, de modo a garantir a sua máxima visibilidade. O passo seguinte trata de mostrar que tal objeto está perdido, é muito difícil de encontrar, já não é o que era ou foi vítima de inqualificáveis maleitas que o afastaram do seu estado primitivo. Por fim, revela-se que as capacidades dos novos média, das novas técnicas, dos novos suportes e dos novos veículos de exibição permitem trazer à vida o 'original' perdido, para deleite das audiências contemporâneas e futuras: "Escusado é dizer que o original (...), que o restauro transforma em performance de DVD's do filme restaurado, é, e permanece, perdido porque a sua perda é o princípio que permite a produção do novo e melhorado original" ${ }^{13}$ (Hediger 2005, 140).Em jeito de súmula argumentativa, cito de novo Paolo Cherchi Usai, quando este afirma que "a noção de restauro 'autêntico' é um oxímoro cultural”"14 (apud Carroll 2005, 20).

Um restauro acaba por se converter, de certo modo, num documentário sobre o seu contexto de produção, ou seja, exibe na sua superfície os motivos que levaram a que tenha sido necessário. E esses motivos prendem-se necessariamente com o estado dos materiais preservados, mas também, e mais prementemente, com a necessidade atual de exibir esses materiais (de novo), de lhes dar

\footnotetext{
${ }^{11}$ Tradução do autor.

12 Tradução do autor.

${ }^{13}$ Tradução do autor.

${ }^{14}$ Tradução do autor.
} 
uma roupagem contemporânea ${ }^{15}$. Por exemplo, a reconstrução de Something's got to Give (1963), de George Cukor, que Marilyn Monroe não pôde terminar (porque morreu durante a rodagem), revela muito mais o desejo económico dos estúdios de produzir mais materiais vendáveis e novos (ou originais) da estrela do que qualquer outra hipótese. Há, no restauro, sempre uma apropriação contemporânea (não só dos olhares, que pode ser maior ou menor) da obra de partida.

\section{Dois exemplos}

A este propósito, chamo a atenção para dois casos curiosos no que respeita à produção de versões conscientes e especulativas de filmes inacabados.

O primeiro foi estreado em 2015 - já que nunca havia sido terminado - e trata-se de um filme de Orson Welles, Too Much Johnson (1938), cujos materiais foram descobertos em Itália, em 2014. O projeto inacabado seria composto por três curtas-metragens mudas, que intervalariam uma produção teatral. Scott Simmon, historiador e arquivista, explica na apresentação do filme pela National Film Preservation Foundation que a montagem que hoje conhecemos é "uma estimativa aproximada [one rough guess]"16 (Simmon 2014) daquilo que o filme poderia ter sido, caso Welles e o seus colegas do Mercury Theatre o tivessem terminado. Contudo, acrescenta que, apesar de ser apenas uma possível montagem, "esforça-se por ser uma montagem informada"17 (op. cit.). O mais surpreendente é que a fundação decidiu disponibilizar ao público também a digitalização em bruto dos materiais descobertos, e o historiador explica que esses materiais estão "disponíveis para visualização na Internet e para descarregar, esperamos que outras reconstruções se sigam"18 (op. cit.). Ou seja, a consciência de que qualquer reconstrução de um filme inacabado é apenas uma estimativa transforma-se num convite aos internautas para tentar a sua vez. Subentende-se, portanto, que qualquer interpretação dos materiais sobreviventes de um filme incompleto e nunca terminado é tão válida como qualquer outra - mesmo que umas se esforcem mais por seguir uma perspetiva historiográfica do que outras.

Igualmente através das potencialidades da partilha de dados na Internet, Garrett Gilchrist criou em 2006 uma plataforma sem fins

\footnotetext{
${ }^{15}$ Ainda que essa não seja, naturalmente, a premissa que dirige a actividade das cinematecas e arquivos públicos de preservação, conservação e restauro. É no entanto a premisse que orienta vários dos detentores de direitos que vêem nos seus arquivos fílmicos um potencial económico.

${ }^{16}$ Tradução do autor.

${ }^{17}$ Tradução do autor.

${ }^{18}$ Tradução do autor.
} 
lucrativos dedicada a reconstruir e restituir a forma desejada por Richard Williams para o seu filme de animação, que acabaria por ser distribuído (fortemente amputado) como Arabian Knight (1995) pela Miramax. Devolvendo-lhe o primeiro título, The Thief and the Cobbler, o restaurador-reconstrutor vem recebendo materiais de vários dos artistas que colaboraram com Williams (o filme tem o recorde de mais anos de produção, num total de 31) e, partindo da sua workprint (e por vezes ultrapassando-a), partilhou versões sucessivamente mais ricas, longas e com maior qualidade de imagem em 2006, 2008 e 2013 - num processo contínuo e necessariamente incompleto (Fenlon 2014), como todos os restauros cinematográficos necessariamente são.

\section{Um filme, múltiplas versões}

Estes dois casos espelham duas noções que me parece importante frisar: (1) a compreensão por parte dos restauradores em causa que o seu trabalho é apenas um, como tantos outros, possíveis olhares sobre um filme, e, apesar de serem olhares educados, conscientes da historiografia, e até eventualmente bem-intencionados, são tão válidos como tantos outros, na medida em que cada restauro constitui um novo original (isto é, resultando o restauro de um processo sucessivo de escolhas, duas equipas com os mesmos dados históricos, os mesmos materiais fílmicos e a mesma tecnologia obteriam naturalmente restauros distintos); (2) é problemática a ideologia que rege muita da prática reconstrutiva, de que mais-émelhor, ou seja, a noção de que re-introduzir mais material (até mesmo material que havia sido cortado, assim como materiais incompletos) traz ao restauro qualidade historiográfica e constitui uma forma de autoridade sobre os restauros anteriores. Poderia apresentar vários exemplos desta perspetiva do restauro (já que é muitas vezes a perspetiva dominante); restringindo-me à prática do restauro em Portugal, chamo a atenção para a re-introdução dos cortes de censura, por exemplo em Os Verdes Anos (1963) de Paulo Rocha (Cinemateca 2015). Este género de casos é naturalmente defensável por inverter uma amputação forçada da obra por uma entidade exterior ao filme. Ainda assim, há que notar que a versão não censurada nunca foi exibida publicamente em Portugal à data da estreia e, como tal, elevá-la a versão definitiva contraria o princípio fundamental enunciado pelo diretor do Arquivo Nacional da Imagem em Movimento - ANIM, Tiago Baptista, de que "é preciso restaurar alguma coisa que tinha sido vista, alguma vez, por alguém” (Lisboa 2017). Há, portanto, uma hierarquia que promove a versão original como aquela com os cortes de censura, ainda que essa seja uma versão fabricada num arquivo e, logo, distante da cópia ideal tipo produzida para o dia da estreia. Uma alternativa pedagógica, praticada pela Cinemateca Portuguesa, passa por, no final da projeção, exibir os cortes de censura que foram re-introduzidos. Só que essa 
escolha altera a natureza da própria experiência fílmica - como se discutirá adiante.

A obsessão pela quantidade tornou-se muito evidente com o mercado do cinema em casa, no qual várias versões de filmes se multiplicam ao sabor do intuito mercantil de vender a mesma coisa com roupagens diferentes. $\mathrm{O}$ investigador Nathan Carroll considera de facto que a crise ontológica do restauro (manifestada pela digitalização) passa exatamente pela necessidade de engaiolar memórias obsoletas e respetivos parâmetros estéticos, num exercício de fetiche nostálgico pelo arquivo (e pelo que dele se perdeu).

O restauro cinematográfico age segundo a assunção implícita de que, se melhores componentes sobreviventes, mesmo que sejam apenas fotogramas únicos, forem encontrados num qualquer futuro, num arquivo ainda por explorar, serão materialmente incorporados na corrente sanguínea da novamente 'restaurada' obra de arte. O trabalho do restaurador cinematográfico é motivado pela obsolescência arquivista da materialidade e da memória do filme, isto é, preservar a autenticidade histórica do cinema como arte tem sempre estado aberto a renegociações do que pode ser disfarçado na nostalgia, ou mesmo, na retórica moralizante do que-poderia-tersido. (Carroll 2005, 18) ${ }^{19}$

Neste sentido, as versões de autor (os director's cut) multiplicam-se e quase invariavelmente não oferecem qualquer melhoria nem acrescento qualitativo às obras que prolongam. Regressando às palavras de Vinzenz Hediger, o director's cut ilustra aliás, de forma perversa, como a ideologia capitalista consegue absorver as suas contradições de uma forma produtiva: convertendo numa eficaz ferramenta de marketing e com forte poder económico e perspetivas de venda aquela que foi a versão que o próprio estúdio de cinema não permitiu que o criador criasse à partida, por questões de natureza comercial, mas que é agora vendida como a verdadeira versão e aquela que deveria ter sido vista desde o princípio (Hediger 2005, 144).

Um caso para interessante reflexão é, nem mais nem menos, o da versão de 1997 da primeira trilogia de Star Wars (1977-1983). George Lucas, o criador e produtor da série, decidiu retocar os filmes que lhe deram sucesso nos anos 1970 e 1980, fazendo ligeiras alterações de montagem e vários reparos digitais (nomeadamente, no que diz respeito às tecnologias presentes no filme, isto é, aos efeitos especiais através dos quais Lucas pretende atualizar tecnologicamente o aspeto dos filmes, no sentido de lhes conferir uma aparente modernidade, negando a própria tecnologia que as originou $\left.^{20}\right)$. O problema é que, para o fazer, o realizador sacrificou

\footnotetext{
${ }^{19}$ Tradução do autor.

${ }^{20}$ Note-se que neste caso a decisão é do próprio autor, ao contrário do que sucedeu no restauro de The Wizard of $\mathrm{Oz}$ (1939) onde se retiraram digitalmente os fios que
} 
aquele que é o mais louvado princípio do restauro, a reversibilidade ${ }^{21}$. "O axioma da reversibilidade significa no restauro cinematográfico que nada no material original deverá ser alterado de tal forma que o restauro não possa ser repetido. 'Reversibilidade' no restauro cinematográfico significa 'repetibilidade","22 (Meyer, Read 2000, 71). O que Lucas operou foi, então, a destruição/alteração permanente dos negativos de câmara, como o explicou o representante de relações públicas da Lucasfilm, citado por Malloy Andrews:

Os negativos dos filmes foram permanentemente alterados com a criação da Edição Especial, e as cópias de primeira geração existentes estão em más condições. (...) Uma vez que estes filmes não representam a visão artística do George, não podíamos investir as extraordinárias somas de tempo e recursos nesse projeto, como o fizemos com a Edição Especial. (...) Queremos que fique claro que não temos planos - agora ou no futuro - de restaurar as primeiras versões. (apud Andrews 2014) ${ }^{23}$

Assim, o que Lucas faz é um processo de reescrita histórica, coisa de que o criador tem plena consciência, já que, à data de lançamento dos DVD, afirmou, "o que acaba por ser realmente importante para mim é de que modo a versão em DVD vai ficar, porque essa é aquela que toda a gente vai recordar. As outras versões desaparecerão. Até mesmo as 35 milhões de cassetes VHS (...) não durarão mais que trinta ou quarenta anos" ${ }^{24}$ (op. cit.). Este caso é um exemplar claro da tensão entre restauro cinematográfico elaborado no sentido de uma atualização para a audiência contemporânea ou dirigido às intenções do criador (ou neste caso, uma combinação dos dois que apaga as versões do passado de forma consciente e propositada, para que a memória do futuro seja a da revisão digital).

\footnotetext{
seguravam os macacos voadores, ou no apagamento das linhas de costura dos filmes em Cinerama, como foi o caso do restauro de How The West Was Won (1962). No entanto este debate complica-se quando se percebe que os fios de The Wizard of $\mathrm{Oz}$ só são hoje visíveis por causa de digitalizações de alta definição, isto é, com os processos analógicos de revelação os fios não eram visíveis e os directores de fotografia e de efeitos especiais jogavam com essas lacunas da definição.

${ }^{21}$ De notar no entanto que este não é uma fenómeno próprio ou exclusivo de George Lucas e da sua série de ficção-científica. A quebra da reversibilidade é comum na história do cinema, vários são os casos de realizadores (no período do cinema mudo, por exemplo) que alteraram definitivamente os seus filmes em versões revistas anos após a sua estreia. Um caso português disto mesmo poderá ser Os Lobos (1923) de Rino Lupo, cuja versão que se conhece hoje é apenas a de 1924 em seis partes, ao contrário da versão em oito partes que estreou nas salas portuguesas (Baptista, 2017, 119). Convirá não desvalorizar que esses processos de revistação, por parte dos autores, não se operavam segundo a protecção cultural do restauro.

${ }^{22}$ Tradução do autor.

${ }^{23}$ Tradução do autor.

${ }^{24}$ Tradução do autor.
} 
Cabe então perguntar: "o que é o filme inteiro"? Aquele que primeiramente foi exibido ao público? Aquele que corresponde à versão do realizador (director's cut)? A versão distribuída comercialmente? A versão censurada e cortada pelos estúdios? Ou o filme que, para todos os efeitos, parece 'completo' (nos possíveis casos de não existir modo de certificar que alguma porção lhes esteja em falta)?

Optar por uma versão em favor de outra não resulta, de modo nenhum, num juízo qualitativo. A este respeito Paolo Cherchi Usai propõe algo que, não sendo uma escolha arbitrária de entre as múltiplas versões do filme, peca ainda pela ambivalência da escolha. Diz ele:

É aqui que o juízo do restaurador se torna crucial, e é aqui que o tratamento da lacuna se enriquece de uma instância ética. Se as cópias visíveis ao público são a preto-e-branco, se temos a possibilidade de apresentar um equivalente a cores, se a cor faz a diferença e se a diferença entre as opções disponíveis influi na nossa capacidade de apreciar o valor da obra, devemos, efetivamente, eleger a hipótese que menos nos ajuda nesta direção? (Usai 1991, 48) ${ }^{25}$

Usai refere-se ao caso particular de The Cossack Whip (1916), de John H. Collins, que apresenta versões com diferentes montagens e colorações. O que parece ser o facto fundamental de escolha para Usai, aquando da definição de uma totalidade, é a questão da visibilidade que o restaurador dá à obra restaurada e a forma como o restauro deve produzir uma obra nova que, de algum modo, exponha o filme na sua melhor versão, isto é, na versão que mais o beneficie de um ponto de vista estético, histórico, formal e cultural (e provavelmente económico) -, com a salvaguarda de que qualquer restauro deverá enunciar claramente quais os elementos do pot pourri.

Não se trata de discutir a validade dos procedimentos alternativos do restauro: o que importa ter presente, e declarar com clareza, é que não se pode dizer 'vi o filme x'; em vez disso, deve dizer-se 'vi a cópia tal do ano tal do filme $\mathrm{x}$ ' ou ainda, 'vi o filme $\mathrm{x}$ numa cópia com a montagem da versão x e com as cores da versão y'. Conclui que:

A nossa honestidade intelectual está salvaguardada, mas também está salvaguardado o nosso prazer de espectadores, e salvaguardado o conhecimento de que cada exemplar de uma época diferente é um 'original', que eleger entre 'originais' diferentes significa eleger entre diversos tipos de lacuna ou de alterações que cada versão comporta, seja na montagem, na coloração ou outras diferenças no

${ }^{25}$ Tradução do autor. 
que respeita à cópia tipo ideal. Aliás, a versão restaurada passará a ser um 'original' (...). (op. cit.) ${ }^{26}$

A proposta de Usai peca, porém por, heuristicamente, se fundar no referido conceito curto de cópia tipo ideal e, como tal, não considerar casos como os que Casper Tybjerg refere num artigo intitulado "The Presentation of Variant Endings" (2003), no qual explora o caso frequente do cinema mudo dinamarquês, em que um filme possuía dois finais diferentes (um final mais feliz para a distribuição doméstica e um mais triste para a distribuição russa) (Tybjerg 2003, 237) ${ }^{27}$. O investigador refere que a prática comum do restaurador é apresentar os dois finais consecutivamente. Tal prática altera de forma profunda o modo como o espectador moderno recebe o filme, convertendo-o (a bem de melhor apreciar o seu valor) num objeto historiográfico, amputando as suas potencialidades narrativas e o envolvimento emocional do espectador, já que este, mal termina o filme, se vê confrontado com um final totalmente oposto e disruptivo. Se, de facto, Usai considera o restauro como um novo original, tal restauro com finais consecutivos é definitivamente novo e não reproduz certamente aquilo a que assistiu o público da estreia, nem qualquer outro público em qualquer outro momento da história em qualquer das versões e mutilações do filme, e verdadeiramente não faz jus ao que o filme terá sido nem participa de uma renovada visibilidade do objeto (a não ser a nível académico, ou a título de curiosidade). De modo semelhante, a exibição de um filme mudo em silêncio é um processo museológico que reduz a ideia de original à materialidade da cópia que se preserva no arquivo e se exibe na sala da cinemateca.

Segundo Hediger, só nos anos 1980 é que os historiadores de cinema e arquivistas começaram a dedicar o seu interesse às questões performativas do filme, em especial no cinema mudo e naquilo que constitui o princípio regulativo desses anos do filmeperformance (por oposição ao princípio vigente do filme-película, que ainda vigora na maioria dos arquivos e cinematecas), em que o filme, mais do que um objeto de um realizador, produtor ou argumentista, era um objeto do exibidor, que o ornamentava e integrava num espetáculo de variedades com efeitos visuais e sonoros síncronos com o correr da película - e, como tal, ver uma obra no cinema de um ou de outro exibidor correspondia a assistir a interpretações

\footnotetext{
${ }^{26}$ Tradução do autor.

${ }^{27}$ A prática de finais alternativos não é naturalmente específica do cinema mudo dinamarquês. No âmbito da filmografia de Manoel de Oliveira há o caso conhecido de A Caça (1963) que possui dois finais, um feliz e outro pessimista - por imposição da censura. Na cópia restaurada pela Cinemateca Portuguesa o filme termina na sua versão pessimista, à qual surge um cartão que informa "Este filme terminava assim na versão original mas a censura exigiu um fim optimista como vão ver a seguir".
} 
possivelmente muito diferentes da mesma obra ${ }^{28}$ (Hediger 2011, 14).

A referida perspetiva museológica (do filme-película) esquece, portanto, que - na maioria dos casos - as obras mudas nunca foram vistas (nem foram criadas com o intuito de serem exibidas) em silêncio. Daí que a sua projeção sem acompanhamento sonoro ou musical esteja factualmente mais distante daquilo que os primeiros espectadores terão visto (aquando da materialização da cópia ideal tipo na tela). Naturalmente que uma aproximação desse evento passado será acompanhar o filme da respetiva obra musical composta, quando preservada. Mas, mesmo nesse caso, pressupõe-se a unicidade dessa composição e supõe-se uma hierarquia entre essa (escrita e preservada) por oposição àquelas que eram improvisadas com base em temas recorrentes - durante a projeção. No caso de não haver qualquer composição preservada, o acompanhamento sonoro (mesmo que em estilos musicais anacrónicos - como se vem tornando comum) constitui, provavelmente, uma experiência mais próxima do original do que a simples amputação - a qual, naturalmente, perturba a visibilidade potencial do filme.

Um exemplo rico deste revisionismo que a banda-sonora promove é o caso das diferentes iterações de Metrópolis (1927), culminando na versão de Giorgio Moroder, de 1984, que se faz acompanhar de músicas pop da década de 1980. Nesse caso, a perspetiva do palimpsesto genealógico ${ }^{29}$, como um acumular histórico e cultural de tudo aquilo que o filme foi agregando ao longo da sua existência, beneficia a leitura do filme como performance pessoal. Através desta perspetiva, a versão de Moroder, que à época do seu lançamento foi muitíssimo criticada por historiadores, arquivistas e críticos de cinema, é, segundo Giorgio Bertellini, a literal corporização da estrutura de palimpsesto de Metropolis.

No contexto do questionamento historiográfico da prática do restauro cinematográfico, Metropolis (1984) não representa um evento caricatural na vida de uma obra de arte. O compositor [Moroder] fez, de facto, aquilo que os historiadores (e os benjamininanos colecionadores de livros) normalmente fazem: ele

\footnotetext{
${ }^{28}$ Tal princípio seria hoje útil para distinguir, por exemplo, as diferenças entre um filme mainstream que se estreia em salas tradicionais, mas também em 3D, em 4DX, em salas IMAX, com velocidades de projecção que ultrapassam os 24 (ou 25) fps e sobem aos 48 (a trilogia de Hobbit de Peter Jackson) ou mesmo os 120. E se o cinema mainstream apresenta exemplos significativos para uma alteração dos princípios regulativos então o cinema experimental e as vídeo-instalações apenas confirmam este panorama, já que a exploração das possibilidades do medium é um dos seus interesses mais recorrentes.

${ }^{29}$ Remeto o leitor para a comunicação "A Favor de uma Teorização do Restauro Cinematográfico, o caso de Metropolis" (2017) onde se descreve largamente este restauro em particular e se apresentam três propostas de teorização da prática do restauro, uma delas, o palimpsesto genealógico de Giorgio Bertellini.
} 
'descobriu' um objeto do passado e re-arrumou-o na sua própria biblioteca cultural, de acordo com as suas capacidades visionárias, ainda que a fim de uma compreensão e apreciação diferente dos texto(s) de Lang. (Bertellini 1995, 279) ${ }^{30}$

Assim, a questão da apropriação dos objetos do passado, ao estilo dos poetas surrealistas ou dos realizadores do found footage, verte-se na prática do restauro, e a versão de Moroder surge como uma interpretação pessoal da partitura que Lang legou. E se uso os termos de Hediger é porque o próprio investigador refere o caso nestes termos. Segundo ele, a versão de Moroder "implica o direito de um restaurador de apresentar uma obra segundo a sua própria visão, i.e., uma noção do filme como obra que inclui o aspeto da performance e recusa limitar as condições identitárias da obra e performance àquelas oferecidas pelo paradigma filológico" 31 (Hediger 2011, 15)

\section{O filme como conjunto de práticas}

A este respeito, chamo a atenção para o artigo de Emile Poppe sobre a edição em DVD do 'restauro' de A Star Is Born (1954) ${ }^{32}$, intitulado "La novellisation du film par le DVD: le cas de A Star Is Born". Em particular quando o autor se refere à versão 'restaurada' como aquela que sugere ou evoca a versão original apesar de, no intuito, se organizar como um best of de materiais autênticos o mais extenso possível. Nesses casos o resultado é "mais que um restauro, é um trabalho de reconstrução arqueológica.” (Poppe 2006, 530). Poppe conclui que "o espectador que vê a versão restaurada (...) não está mais dentro da ficção; ele assiste ao texto de um restauro em que alguns elementos lhe são dados através do filme e da sua ficção." e ainda que "os restauradores não resolvem da melhor forma as lacunas. Mas essa não é aqui a questão, é uma alteração do estatuto do filme, uma alteração da sua significação"33 (op. cit., 531). Esta mudança de estatuto é aquilo que se evidencia também nos dois finais consecutivos dos filmes dinamarqueses mudos referidos por Tybjerg, ou na exibição silenciosa de filmes mudos.

Como referido nos casos de Too Much Johnson e The Thief and the Cobbler, a Internet e a partilha de ficheiros digitais num ambiente de banda larga (onde as imagens em movimento são hoje frequentemente consumidas e quase sempre produzidas) ou a capacidade de armazenamento de memória de um DVD ou Blu-Ray

\footnotetext{
${ }^{30}$ Tradução do autor.

${ }^{31}$ Tradução do autor.

${ }^{32}$ Restauro que inclui sequências do musical onde já só a banda de som se conserva e à qual foi acrescentada uma montagem de fotografias de cena, assim como a reposição de várias sequências que haviam sido cortadas para a versão que foi distribuída.

${ }^{33}$ Tradução do autor.
} 
permitem uma multiplicação da natureza do filme, isto é, permitem que um objeto de mercado intitulado, por exemplo, The Complete Metropolis, inclua todas as versões (ou tantas quanto possível) que o filme foi tendo ao longo da sua existência e, a partir de um simples controlo remoto (ou de um conjunto de cliques), o espectador possa escolher a versão a que deseja assistir (ou uma combinação delas, à imagem daquilo que são as recomendações de Paolo Cherchi Usai, e evitando o embate emocional de assistir a versões narrativas totalmente opostas do mesmo filme, como advertiu Tybjerg).

Esta mudança de estatuto do filme resulta num câmbio muito significativo na forma como lidamos como os objetos fílmicos, na medida em que as qualidades propriamente narrativas dos filmes deixam de ser a chave do entretenimento. Pelo contrário, é o interesse historiográfico que compara incessantemente as várias versões aquele que prende o espectador. Assim, o cidadão comum, o cinéfilo interessado ou o investigador tornam-se parte integrante da construção histórica que o objeto fílmico propõe e a qualidade disruptiva de dois finais opostos para o mesmo filme surge como fator extra na compreensão (tão grande quanto possível) da história das versões que o filme foi tomando.

Considere-se agora o argumento da visibilidade, que afirma que a concentração num único objeto das melhores partes das várias versões é algo que foca a atenção dos espectadores/consumidores/estudiosos. É certo que um objeto multiplicado perde em unidade e em noção de completude; no entanto, esta opção é tão mais verdadeira quanto melhor evidencia que a construção de um objeto concentracional é uma falácia histórica (útil, é certo, mas uma falácia, de qualquer forma).

Semelhante proposta fez Vinzenz Hediger, quando apresentou o original como um "conjunto de práticas [a set of practices]" (Hediger 2005, 147), ou seja, um conjunto de versões combinadas bundled -, apenas limitadas pela impossibilidade de o próprio trabalho historiográfico ser exaustivo.

Segundo esta perspetiva, o original ainda tem que ser dado como perdido. Dividido num conjunto de práticas, o original está ainda mais completamente perdido do que a retórica do original aceitaria, na medida em que não se permanece com um ideal de totalidade e se substitui a procura por um único e verdadeiro texto original pela procura da totalidade de todas as práticas que constituem o original como um conjunto de práticas. A pesquisa histórica precisa sempre de aceitar como facto único que um conjunto completo de factos não existe. Uma historiografia do cinema que defina o original como um conjunto de práticas terá de ter em conta essa limitação. (op. cit. $)^{34}$

\footnotetext{
${ }^{34}$ Tradução do autor.
} 
Segundo esta perspetiva, o realizador-restauradorreconstrutor deverá ser um revelador de olhares (seus e de outros), apenas limitado pelas versões que o arquivo contém e pela sua consciência especulativa no manuseio dessas versões. E o filme, enquanto objeto transacionável, surge agora como estrutura multicamadas, no qual as várias versões do filme convivem lado a lado em meio digital, quer num torrent ou num DVD/Blu-ray. Assim, um filme de uma dada metragem multiplica-se tantas vezes quantas o número de versões diferentes. $E$, na medida em que $o$ espectador/utilizador poderá percorrer as várias versões e remisturá-las à sua medida, então, nesse caso, a duração de um objeto poderá ser tão longa quanto as combinações matemáticas que o dispositivo eletrónico possibilite (que tenderão para o infinito, produzindo assim versões praticamente individualizadas para cada espectador/utilizador) - e o objeto aproxima-se das experiências semelhantes das database narratives em mercado de cinema em casa.

\section{Um caso português de um filme como conjunto de práticas}

Douro, Faina Fluvial é um caso curioso do ponto de vista do restauro, já que é um dos casos nacionais em que mais versões diferentes existem do mesmo filme. A obra de estreia de Manoel de Oliveira foi apresentada pela primeira vez ao público em 1931 no V Congresso Internacional da Crítica pela mão de António Lopes Ribeiro. Este conhecera o projeto, ainda em fase de montagem, quando Oliveira o enviou para a Ulisseia Filmes a fim de produzir uma versão finalizada (já que, segundo o mito - que o próprio realizador fixou mais tarde em Porto da Minha Infância [2001] -, foi uma mesa de bilhar o local de montagem do filme). A versão apresentada na estreia era muda. Três anos depois, Douro... estreia comercialmente com Gado Bravo (1934), filme realizado pelo próprio Lopes Ribeiro, numa versão sonorizada com uma partitura de Luís Freitas Branco e "a partir dessa data, pela necessidade de inclusão da banda de som, o filme passou a ser projetado com a banda de imagem cortada" (Costa 2006). Esta foi a versão que se conheceu do filme, sonorizada e truncada na imagem. Só nos anos 1990 se descobriu o negativo de câmara em França e, com este, a Cinemateca Portuguesa, com o auxílio do National Film Archive (ainda não existia ANIM), iniciou um restauro que seria apresentado em 1992, o original mudo.

Contudo, em 1995 o autor decidiu produzir uma nova versão, também não truncada, mas com uma montagem diferente - corrigida por Manoel de Oliveira, que "segundo ele próprio, retoma exatamente aquilo que era a ordem inicial dos planos” (op. cit.), já que Lopes Ribeiro havia alterado, sem consentimento do realizador, a montagem do filme para a sua distribuição comercial -, passando o filme de cerca de 21 minutos na versão de 1934 para cerca de 18 minutos nesta nova versão, e acrescido de uma banda sonora 
diferente, a música Litanie du feu et de la mer, de Emmanuel Nunes Oliveira "recriou a sua obra" (op. cit.). Esta versão reescrita teve estreia na Cinemateca Portuguesa em 18 de junho de 1996, e trata-se de um caso de um restauro segundo as intenções do criador, mesmo quando estas intenções são conflituosas.

José Manuel Costa chega mesmo a afirmar que este "[é] um caso único de work in progress, pois que Oliveira jamais deixou de dialogar com este filme e de o modificar" (op. cit.). E, de facto, nesta historiografia das versões de Douro Faina Fluvial contam-se quatro versões distintas: a versão muda apresentada no $\mathrm{V}$ Congresso Internacional da Crítica; a versão da estreia comercial do filme remontada, amputada e musicada; o restauro da primeira versão muda; e a remontagem e re-musicação do restauro da versão muda.

Curiosamente, e a bem do argumento que aqui apresentei, três versões de Douro Faina Fluvial estão hoje editadas em DVD como extras do filme Aniki-Bóbó (1942) - a primeira longa-metragem de Manoel de Oliveira -, às quais se junta uma introdução e um comentário do próprio José Manuel Costa - note-se que são três versões, na medida em que se confundem a versão de estreia e o restauro dessa versão como uma só identidade fílmica.

Com vista a facilitar o processo de análise e comparação das três versões - processo que pretendo célere, já que não é esse o foco deste artigo -, tomei inspiração no "ensaio audiovisual 'interativo"”35 proposto por Kevin B. Lee $(2017)^{36}$ e produzi um simples vídeo que divide o écran em três partes (uma para cada versão - que sincronizei apenas nos primeiros segundos) e subdivide as bandas sonoras (das versões de 1934 e 1994) entre a saída esquerda e direita do som estéreo ${ }^{37}$. Assim, pode ver-se, em simultâneo, as três versões (percebendo rapidamente como diferem entre si, tanto na organização dos planos como na duração dos mesmos), como também cada uma delas individualmente, através da "interacção física com as imagens em movimento"38 (op. cit.) e a escolha do auscultador respetivo.

O que se torna imediatamente evidente é que a remontagem de 1994 altera de forma muito manifesta a ordem dos planos, ao contrário das versões de 1931 e 1934, que diferem quase só na duração de cada um deles (a versão de 1934 parece prolongar todos os planos, promovendo um desacerto com a versão muda que, no final desta, está perto de um minuto). No que respeita à banda

\footnotetext{
${ }^{35}$ Tradução do autor.

${ }^{36} \mathrm{O}$ investigador e crítico criou um ensaio sobre Ji-geum-eun-mat-go-geu-ddaeneun-teul-li-da (2015), de Hong Sang-soo, intitulado 323. Right Now, Wrong Then de tal modo que o espectador pode optar (cobrindo parte da sua visão com as mãos) ver uma versão com ou sem spoilers.

${ }^{37}$ Disponível em: https://youtu.be/jaJpAfVLOLI.

${ }^{38}$ Tradução do autor.
} 
sonora, a composição de 1994 introduz uma grande diferença de tom. A música de Emmanuel Nunes é muito mais serena e contrasta fortemente com a banda sonora épica de Luiz de Freitas Branco. A este respeito, convirá notar o comentário publicado de Vasco Pimentel - conhecido técnico de som do cinema português -, que colaborou com Manoel de Oliveira na remontagem de Douro a partir da composição de Emmanuel Nunes (que tem, originalmente, mais de 45 minutos de duração):

Fui eu que remontei, plano a plano, o Douro, Faina Fluvial, quando o Manoel de Oliveira decidiu, em 1992 (...), que era com esta música que ele queria que o filme fosse visto para todo o sempre. Não me deixou, sequer, abreviar meio segundo uma nota que fosse (ou a uma pausa, estes silêncios). Não senhor: em caso de dúvida, modificava-se a duração dos planos. Levámos um dia inteiro nisto. Eu sugeria os pontos onde o filme ganharia se nós interviéssemos; dessincronizava um pouco a coisa, e mostrava-lhe como poderia ficar; e o Manoel é que matava a cabeça para chegarmos ao resultado desejado: cortamos quatro fotogramas aqui, ganhamos mais à frente, cortamos mais 12 , três planos mais adiante. $\mathrm{E}$ começar...? E acabar...? (comunicação pessoal, 13 de agosto, 2017)

Este testemunho é importante, na medida em que revela que foi exatamente a banda-sonora escolhida por Oliveira que ditou a remontagem do filme, contrariamente ao que é habitual na musicação de filmes mudos quando o realizador não está vivo. Isto é, não foi a composição musical que procurou complementar a banda de imagem, mas sim a remontagem que procurou encontrar sincronias e dessincronias- aspeto que José Manuel Costa muito elogia:

a ligação estabelecida por Oliveira releva sempre do contraponto e, no limite, parece funcionar totalmente contra o próprio ritmo da montagem, ou, pelo menos, contra o seu ritmo exterior. Em si mesma, a música não é colocada para ampliar a intensidade visível, ou mais superficial, das imagens. A relação entre uma banda e outra é infinitamente mais subtil e baseia-se justamente na recusa total da redundância. (...) São precisamente [a] tensão e [o] silêncio que acabam afinal por ampliar - como se o transportasse para uma outra dimensão - o ritmo profundo, interno, destas imagens. (...) Oliveira procurou que a música nos ajudasse a 'escutar' as suas imagens. Fazendo isso, respeitou essas imagens, ao mesmo tempo que respeitou o espírito da época em que elas foram realizadas. (Costa 2006)

Uma conclusão evidente da comparação entre as três versões é que de facto Manoel de Oliveira construiu uma versão que muito se distancia daquela que foi a sua estreia na realização (ainda que ambas partilhem o mesmo título). Isto traduz a importância da noção do filme como conjunto de práticas, já que a edição de uma das versões, sem o acompanhamento da outra, poderia levar a crer que existe uma cópia definitiva - original ou autêntica - do filme, o que não é o caso. Mas, mais do que isso, a visão simultânea (ou consecutiva) das três 
versões ajuda a traçar o arco criativo e estético que dominou o próprio realizador no intervalo de mais de sessenta anos que separa a mais antiga da mais recente versão: das vanguardas do final do cinema mudo até à claridade quase clássica do final da sua obra.

Este é pois um caso do filme como um conjunto de práticas que encontram no suporte digital de um DVD um meio para dar a conhecer como objeto historiográfico as diferentes versões que um filme foi tomando - solução essa que, de certo modo, mima para o uso doméstico o próprio trabalho da Cinemateca Portuguesa que já havia exibido as três versões do mesmo filme nas suas sessões regulares e que naturalmente, como arquivo, conserva separadamente as diferentes versões do filme, não as confundindo e contextualizando, sempre que possível, a sua exibição pública.

Permite-se assim a exploração do espectador e a comparação das diferentes versões, mas, mais importante, a compreensão do filme como conjunto de práticas no meio da comercialização do objeto fílmico (em DVD) chama a atenção do consumidor/espectador para as problemáticas próprias do restauro e da fixação dos termos fundamentais, originalidade e autenticidade permeando-se assim de uma componente pedagógica que converte o objeto de consumo numa ilustração da vida material (e performática) do filme e das atribulações históricas das suas exibições públicas. Isto é, o filme como conjunto de práticas adquire uma componente didática, no sentido de colocar nas mãos do, anteriormente passivo espectador o domínio sobre que versão prefere ver (ou que versão prefere construir). Assim, os cerca de 20 minutos da obra de estreia de Manoel de Oliveira convertem-se em perto de 60 minutos, na edição de DVD, e esses cerca de 60 minutos multiplicam-se pelos ritmos próprios de cada espectador que, a qualquer momento, para e transita de versão em versão, formando o "seu" Douro Faina Fluvial e sendo esta a expressão máxima da sua cinefilia: prolongar indefinidamente o filme, aos limites da sua própria dedicação à história (e historiografia) do seu objeto de afeto.

\section{Conclusão}

A proposta deste artigo limita-se, afinal, a fazer pouco mais do que transparecer para o universo do cinema doméstico (na forma de DVD) aquela que no fundo já é a prática dos arquivos cinematográficos um pouco por todo o mundo (no que respeita à preservação, arquivamento e conservação de diferentes versões de uma mesma obra). A este propósito, convirá talvez chamar a atenção para as palavras de Alfonso Del Amo García, Chefe da Secção do Fundos Fílmicos da Filmoteca Española, que, num artigo intitulado "Archivando Versiones - La Catalogación de Los Fondos Fílmicos" (2013), explica os quatro níveis pelos quais a instituição para a qual 
trabalha cataloga as diferentes versões de uma mesma obra ${ }^{39}$. Amo García explica que:

A consideração dupla dos materiais como pertencentes a uma versão ou variante da obra e como originais ou elementos que possam vir a ser utilizados para a reprodução ou acesso apresentouse como a fórmula mais adequada para responder ao conjunto de questões derivadas do facto de se considerar que as obras audiovisuais funcionam numa cadeia de reproduções. (Amo García $2013)^{40}$

O arquivista conclui que "é portanto o modo de acesso o que finalmente determinará as características da receção para cada obra" e esse modo de acesso quer-se tão preciso e desenvolvido quanto possível (a partir das informações que o arquivo e os seus materiais fornecem). Neste sentido, é natural pensar-se que a melhor forma de transportar esta ideologia para o consumo caseiro de cinema passa exatamente por encarar o filme como um conjunto de práticas que o distende nas suas múltiplas versões arquivadas.

Compreender um filme não como uma obra una e definitiva, mas sim como um objeto plural e múltiplo que evidencia a história dos seus dispositivos e a enverga como manifestação da sua historiografia material é deixar de entender o filme como o evento que ocorre num intervalo limitado de tempo em frente a um ecrã para passar a entendê-lo como algo que se propaga no tempo (cuja duração se distende) e no espaço dos vários momentos em que o espectador regressa a uma das várias versões disponíveis (algumas delas construídas pelo próprio) e, mais do que isso, como uma entidade em permanente atualização e sempre lacunar. Neste sentido, a ideia de uma "versão virtual”, para usar uma expressão de Cristina Álvarez López, cunhada a propósito das novas formas de ver cinema em casa (e das edições de diferentes versões de filmes, versões estendidas, cenas cortas transformadas em extras de DVD, etc.), é de grande utilidade, pois de facto, como afirma a crítica e investigadora, "o lugar desta nova versão [do filme, a versão virtual] é o cérebro do espectador. O cérebro é o écran, o suporte e o programa onde se alojam as películas, talvez (...) esta possa ser a

\footnotetext{
${ }^{39}$ Nível 1, aquilo a que se poderia chamar, "de forma geral, inexata e abusiva" (Amo García, 2013), a versão de estreia. Nível 2, inclui as variações de uma obra produzidas para a difusão em áreas ou meios cultural, linguística ou tecnicamente diferentes, as derivações obtidas por reproduções de cópias ditas originais e também os materiais produzidos no decorrer da produção do filme (materiais cortado, os diversos takes de uma cena, trailers produzidos à posteriori para o filme, etc.). Nível 3 e nível 4 referem-se a uma avaliação qualitativa no sentido da sua importância para a conservação da obra em causa, isto é, um material é catalogado no nível 3 caso possa vir a ser fundamental para a preservação de uma das versões do filme e no nível 4 caso as características técnicas e estado de conservação desse material possa vir a ser valiosa no referido restauro.

${ }^{40}$ Tradução do autor.
} 
imagem mais certeira da multiversão do futuro" (Álvarez López $2013)^{41}$.

Pensar o cinema como a articulação dos conceitos, filme como conjunto de práticas e a versão virtual, é aceitar que cada obra se monta diante de cada espectador e que é cada um desses espectadores que determina as características do "seu" filme, incluindo, naturalmente a duração e a musicalidade.

\section{BIBLIOGRAFIA}

Amo García, Alfonso del. 2013. "Archivando Versiones: La catalogación de los fondos fílmicos”. Caimán Cuadernos de Cine (15): XXVIII-XXX (abril). Madrid: CAIMAN Ediciones.

Álvarez López, Cristina. 2013. "Un filme que solo existe en la mente del espectador”. Caimán Cuadernos de Cine (15): XXVI-XXVII (abril). Madrid: CAIMAN Ediciones.

Andrews, Mallory. 2014. "A "New" New Hope: Film Preservation and the Problem with 'Star Wars'”. PopOptiq [Em Linha, consult. 12 Out. 2016]. Disponível na internet: http://www.popoptiq.com/a-new-new-hope-filmpreservation-and-the-problem-with-star-wars/

Baptista, Tiago. 2008. As Cidades e os Filmes, uma biografia de Rino Lupo. Lisboa: Cinemateca Portuguesa - Museu do Cinema.

Benjamin, Walter. 2010. "A Obra de Arte na Era da sua Reprodutibilidade Técnica”. Sobre Arte, Técnica, Linguagem e Politica, trad. M. Luz Moita, 71-113. Lisboa: Relógio D’Água [orig. 1936-39].

Bertellini, Giorgio. 1995. "Restoration, genealogy and palimpsests. On some historiographical questions”. Film History (7): 227290. Londres: John Libbey \& Company.

Cinemateca Portuguesa - Museu do Cinema, 2015. "Os Verdes Anos em DCP, um exemplo de restauro digital”. Cinemateca (Dez): 11. Cinemateca Portuguesa - Museu do Cinema.

Carroll, Nathan. 2005. "Unwrapping Archives: DVD Restoration Demonstrations and the Marketing of Authenticity". The Velvet Light Trap (56): 18-31. Austin: University of Texas Press.

Costa, José Manuel. 2006. "Douro, Faina Fluvial”. Textos Cinemateca Portuguesa (94): 281-284. Lisboa: Cinemateca Portuguesa.

${ }^{41}$ Tradução do autor. 
Fenlon, Wesley. 2014. "Thieves, Cobblers, and Fan Edits: The 50-Year Odyssey of an Animated Masterpiece”. Tested [Em Linha, consult. 12 Out. 2016]. Disponível em:

http://www.tested.com/art/movies/44961-thieves-cobblersand-fan-edits-the50_year-odyssey-of-an-animatedmasterpiece/

Fossati, Giovanna. 2010. From Grain to Pixel, The Archival Life of Film in Transition. Amesterdão: Amsterdam University Press.

Hagener, Malte. 2014. "How the Nouvelle Vague Invented the DVD: Cinephilia, new waves and film culture in the age of digital dissemination”. Aniki v.1 (1): 73-85. AIM. Disponível em: http://aim.org.pt/ojs/index.php/revista/article/view/61/htm 1 .

Hediger, Vinzenz. 2005. "The Original is Always Lost: Film History, Copyright Industries and the Problem of Reconstruction”. In Cinephilia: Movies Love and Memory, Marijke de Valck, Malte Hagener (ed.), 135-151. Amesterdão: Amesterdam University Press.

Hediger, Vinzenz. 2011. "Original Work Performance. Film Theory as Archive Theory". In Quel che brucia (non) ritorna - What Burns (Never) Returns - Lost and Found Films, Simone Venturini, Giulio Buris (ed.). Pasian di Prato: Campanotto Editore.

Jamieson, Krista. 2013. Ethics \& Film Restoration Theor(ies): A Comparative Study of the Concept of "Original" in Restorations of Le Voyage dans la Lune [Tese de mestrado, em linha, consult. 11 Out. 2016]. Amesterdão: Department of Media Studies, Universiteit van Amsterdam. Disponível em: dare.uva.nl/document/498352.

Jenkins, Henry 2007. "The work of theory in the Age of Digital Transformation". In A Companion to Film Theory, Toby Miller, Robert Stan (eds.), 234-261. Oxford: Blackwell Publishing Ltd..

Lee, Kevin B.. 2017. "Video Essays from 2016 - Emerging from Screens Big and Small". Harun Farocki Institut Residency. [Em linha, consult. 20 Abril. 2017]. Disponível em: https://residency.harun-farocki-institut.org/2017/03/videoessays-from-2016-emerging-from-screens-big-and-small/.

Lisboa, Ricardo Vieira. 2017. “Tiago Baptista: 'É importante abraçar a diferença entre a película e o digital'”. À pala de Walsh. [Em linha, consult. 20 Abr. 2017]. Disponível em: http://www.apaladewalsh.com/2017/04/tiago-baptista-eimportante-abracar-a-diferenca-entre-a-pelicula-e-o-digital/.

Meyer, Mark-Paul; Read, Paul. 2010. Restoration of Motion Picture Film. Butterworth-Heinemann. 
Pimentel, Vasco. 2017, 13 de Agosto. "Não estou farto de vos dizer que a minha vida é lendária?” [Facebook]. [Em linha, consult. 1 Dez. 2017]. Disponível em:

https://web.archive.org/web/20171201163418/https://www. ok.com/vasco.pimentel.5/posts/10213650404792867.

Poppe, Emile. 2006. "La novellisation du film par le DVD: le cas de $A$ Star Is Born. Discours fictionnels, discours factuels: le tissage d'extratextualités". In Il racconto del film. La novellizzazione: dal catalogo al trailer / Narrating the Film. Novelization: From the Catalogue to the Trailer, Alice Autelitano, Valentina Re (eds.), 527-534. Udine: Forlaget Forum.

Simmon, Scott. 2014. "Too Much Johnson: The Films Reimagined". National Film Preservation Foundation [Em linha, consult. 12 Out. 2016]. Disponível em:

http://www.filmpreservation.org/preserved-films/screeningroom/too-much-johnson-reimagined.

Tybjerg, Casper. 2003. "The Presentation of Variant Endings". Film and its Multiples, 237-240. Udine: Forlaget Forum.

Usai, Paolo Cherchi. 1991. "El Filme Que hubiera podido ser; o, El análisis de las lagunas considerado como una ciencia exata", trad. Elena Vilardell. Revista Archivos de La Filmoteca Historia y arqueología del cine (10): 42-53. Valência: Generalitat Valenciana. 